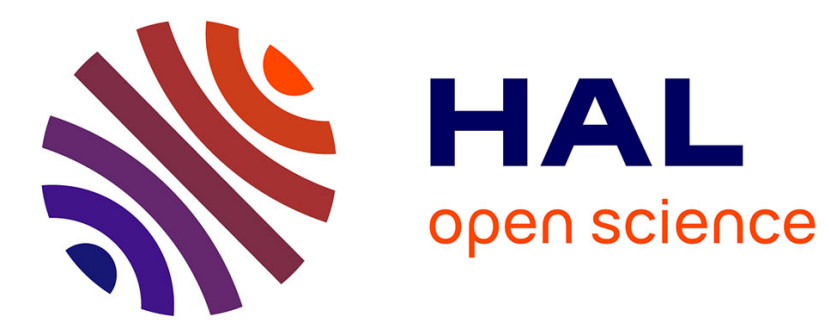

\title{
ELIN: A Framework to Deliver Media content in an Efficient way Based in MPEG Standards
}

Jordi Casademont, Ferran Perdrix, Martin Einhoff, Josep Paradells, Georg Dummer, Anne Boyer

\section{- To cite this version:}

Jordi Casademont, Ferran Perdrix, Martin Einhoff, Josep Paradells, Georg Dummer, et al.. ELIN: A Framework to Deliver Media content in an Efficient way Based in MPEG Standards. 2005 IEEE International Conference on Web Services - ICWS'2005, Jul 2005, Orlando/USA, pp.841-842. inria00000816

\section{HAL Id: inria-00000816 \\ https://hal.inria.fr/inria-00000816}

Submitted on 21 Nov 2005

HAL is a multi-disciplinary open access archive for the deposit and dissemination of scientific research documents, whether they are published or not. The documents may come from teaching and research institutions in France or abroad, or from public or private research centers.
L'archive ouverte pluridisciplinaire HAL, est destinée au dépôt et à la diffusion de documents scientifiques de niveau recherche, publiés ou non, émanant des établissements d'enseignement et de recherche français ou étrangers, des laboratoires publics ou privés. 


\section{ELIN: a framework to deliver media content in an efficient way based in MPEG standards}

\author{
Jordi Casademont \\ Technological University of \\ Catalonia (UPC) \\ jordi.casademont@ \\ entel.upc.es \\ Josep Paradells \\ Technological University of \\ Catalonia (UPC) \\ teljpa@entel.upc.es
}

\author{
Ferran Perdrix \\ Diari Segre \\ fperdrix@diarisegre.com \\ Georg Dummer \\ Forschungszentrum Informatik \\ an der Universitaet Karlsruhe \\ Dummer@fzi.de
}

\author{
Martin Einhoff \\ Fraunhofer Institute for \\ Computer Graphics (IGD) \\ Martin.Einhoff@ \\ igd.fraunhofer.de
}

\author{
Anne Boyer \\ Loria INRIA Lorraine \\ Campus Scientifique \\ Anne.Boyer@ \\ univ-nancy2.fr
}

\begin{abstract}
Nowadays, technologies involved in Web information distribution services are evolving to adapt themselves to new user requirements. Usually, these new technologies are used separately. ELIN (Electronic Newspaper Initiative) project is an European Commission funded project, that tries to integrate the newest standards and technologies involved in multimedia delivery applied to web newspapers. It has as objective the delivery of any type of media format to any kind of user terminal in an efficient way. In order to do that, it takes the approach of using MPEG standards: $M P E G-4$ for video delivery, MPEG-7 for data classification and MPEG-21 for data management and adaptation. So it integrates the totality of solutions provided for the MPEG group.
\end{abstract}

\section{Introduction}

Web news publishing is evolving fast, as the majority of Internet services, and nowadays this service is trying to adapt information to a way that best fits user's interests in order to increase its usage. It is thought that in order to have a good acceptation, Internet newspapers have to adapt themselves to the needs and profiles of its users.

This adaptation can be seen from two points of view. The first one is adaptation on personal interests, or personalization and the other of adaptation is data adaptation that includes transcoding of formats, resizing of images or recoding for higher levels of compression according to user's accessing device.

ELIN system is a news delivery platform that uses MPEG standards to delivery data and a set of algorithms to personalize data for the users.

\section{System architecture}

ELIN system has three main subjects: the application server, the content producer, and the consumer. The content producer site is provided by an authoring tool that easily enables journalists to build news in ELIN format. The consumer can access ELIN data using a MPEG-4 Media Player, or simply using a HTML browser. With the first one, the user is able to access to the whole functionalities of the system while with the second there apply several restrictions. The reason of enabling access with HTML browsers is due to the possibility that the user may want to get information from a low capabilities devices (PDA or smart phone) that don't support MPEG-4 players.

In the server site, there run several server applications that store media resources and their describing metadata, control the access of users, personalize and adapt data, download media resources using MPEG-4 streams or HTTP (Hyper Text Transfer Protocol) protocol and send notifications of important news using e-mail, instant messaging, SMS (Short Message Service) or MMS (Multimedia Message Service). Finally, the system also provides a 3D environment communication tool. This $3 \mathrm{D}$ community 
environment enables the users to share data resources and to communicate between them with a secure videoconference system.

\section{Usage of MPEG standards}

The Moving Picture Experts Group (MPEG) have found the need of tools for the description of multimedia content and the interaction with content and players, so they developed two new standards, MPEG-7 and MPEG-21. ELIN system is one of the first frameworks to make use of the whole facilities provided by MPEG standards.

MPEG-4 is a standard, which describes binary streams for efficient compression of visual and audio data. ELIN uses MPEG-4 to provide interactive news.

MPEG-7 provides a rich set of tools for completely describing multimedia content. In ELIN, we use MPEG-7 in order to store semantic metadata about news and user profiles. In addition, we decided to use IPTC (International Press Telecommunications Council) classification system. IPTC is one of the most used classifications in the edition world.

MPEG-21 is an open standards-base framework for multimedia delivery and consumption. It aims to enable the use of multimedia resources across a wide range of networks and devices [1].

MPEG-21 is based on two essential concepts: the definition of a fundamental unit of distribution and transaction, the Digital Item (DI), and the concept of users interacting with DIs. In particular, part 7 of MPEG-21, also called DIA (Digital Item Adaptation) takes into account all issues related with terminal adaptation, session maintenance an user localization.

MPEG-21 DIA defines a set of descriptors and tools to enable transparent use of multimedia resources across different networks and devices using media adaptation. In the context of MPEG-21, a Digital Item is defined as a structured digital object (a XML file) with a standard representation that can describe a user or a multimedia resource. The basic idea is to have different types of DI describing groups of user parameters.

ELIN uses MPEG-21 for news classification and terminal adaptation. For the first function, each news, add and media resource has been assigned a XML file named Content_DI, that using MPEG-7 metainformation describes and classifies this item (more details in next section).

For adaptation and personalization, each user has been assigned a XML file named Context DI. This one includes user preferences and capabilities of the terminal and network from where the user is accessing the system. This Context DI has also session information and changes during runtime.

In order to know user's device capabilities the system uses an hybrid procedure which is based in HTTP header parameters plus a Java Script software that is executed into a browser at the client side.

\section{Conclusions}

This paper presents a toolkit that integrates the newest developed standards and technologies in multimedia delivery in order to build an on-line newspaper. One of the main objectives has been to make use of MPEG standards: MPEG-4 for video delivery, MPEG-7 for data classification and MPEG21 for data management and adaptation.

This toolkit enables to distribute data in video format (MPEG-4) and HTML (this case will be used only for low capabilities terminals). Data can be displayed using media players or inside a 3D environment that can be used also to communicate users. The system has a smart agent, used to personalize news, based on user profiles and collaborative filtering, in that way we select the most important news for each user. Information is adapted for user's terminal: standard PCs, PDA or also smartphones are considered. In order to adapt information a device capabilities discovering procedure plus a registration phase using SIP are implemented. Finally, the toolkit has an alert system that can send important notifications to clients using an instant messaging system, e-mail, MMS or SMS.

\section{Acknowledgements}

We want to acknowledge the other partners that have participate in the project: Grupo Alamo, Linkoepings Universitet and Aktiegolaget Oestgoeta Correspondenten.

This work was funded by the Commission of the European Communities and the CICYT project TIC2003-01748.

\section{References}

[1] I. Brunet, R. Van de Walle, K. Hill, J. Bormans, F. Pereira, "MPEG-21: Goals and Achievements", IEEE Multimedia, Vol. 9, No. 2, October-December 2003, pp. 6070. 